\title{
THE IDIOMATIC MEANING OF 成语 CHENGYU WHICH HAS NATURAL ELEMENTS
}

\author{
MAKNA IDIOMATIK成语CHÉNGYǓ YANG BERUNSUR ALAM
}

https://journal.fbbunsada.id/bambuti/article/view/xxx

\author{
Desy Veronica \\ misshablack66@gmail.com \\ Universitas Darma Persada
}

\author{
Yulie Neila Chandra \\ ync.puellabona@gmail.com \\ Universitas Darma Persada
}

\begin{abstract}
Mandarin is rich in vocabulary, including the form of 成语chéngyǔ, which is one of the most important parts in Mandarin. Every 成语chéngyŭ has its own background story, including history. Therefore, to understand the meaning of 成语chéngyǔ must understand the background of the story from 成语chéngyǔ. This article describes the idiomatic meaning of 成语chéngyŭ which has natural elements contained in the book of 成语故事Chéngyǔ Gùshi. Each Han character ( 汉字 Hànzi) that becomes an element in成语chéngyǔ does not reflect the overall meaning of the forming element, so that in general the 成语chéngyŭ has idiomatic meaning. The method used in this writing is qualitative descriptive. There are 21 成 语chéngyǔ with natural elements in the book of 成语故事 Chéngyŭ Gùshi, however only one 成语chéngyǔ which contains partial idiom meanings, the other 20 of 成语 chéngyŭ contains the full idiom meaning because of the forming elements do not reflect the idiomatic meaning. 成语chéngyŭ has a syntactic function in the sentence, as well as functions as advice, satire, and also praise to people indirectly.
\end{abstract}

Keywords: 成语chéngyǔ, natural elements, idiomatic meanings, partial idioms, full idioms

Abstrak. Bahasa Mandarin kaya akan kosakata, antara lain berbentuk 成语 chéngyŭ, yang merupakan salah satu bagian terpenting dalam bahasa Mandarin. Setiap 成语chéngyǔ memiliki latar belakang cerita tersendiri, termasuk sejarahnya. Oleh karena itu, untuk memahami makna sebuah 成语chéngyŭ harus memahami latar belakang cerita dari 成语chéngyǔ tersebut. Artikel ini memaparkan makna idiomatik 成语chéngyŭ yang berunsur alam yang terdapat di dalam buku 成语故事chéngyŭ gùshi. Setiap karakter Han (汉字 Hànzi) yang menjadi unsur dalam sebuah 成语chéngyǔ tersebut tidak mencerminkan makna keseluruhannya dari unsur pembentuknya, sehingga pada umumnya成语chéngyŭ memiliki makna idiomatik. Metode yang digunakan dalam penulisan ini adalah deskriptif kualitatif. Terdapat 21 成语chéngyǔ berunsur alam dalam buku 成语故事 chéngyǔ gùshi, namun hanya satu 成语chéngyǔ yang mengandung makna idiom sebagian, 20 成语chéngyŭ lainnya mengandung makna idiom penuh karena unsur 
pembentuknya tidak mencerminkan makna idiomatiknya. 成语chéngyǔ memiliki fungsi sintaksis di dalam kalimat, serta berfungsi sebagai nasihat, sindiran, dan juga pujian kepada orang secara tidak langsung.

Kata Kunci: 成语chéngyǔ, unsur alam, makna idiomatik, idiom sebagian, idiom penuh

\section{PENDAHULUAN}

Dalam linguistik terdapat kajian khusus mengenai makna yang dikenal dengan semantik. Menurut Palmer (1981:1), semantik adalah istilah yang merujuk dalam suatu studi tentang makna. Berbagai teori tentang semantik berhubungan dengan makna, sehingga dapat diungkapkan bahwa setiap kata itu mempunyai makna atau arti yang berbeda-beda. Menurut Chaer (1994: 289-296), jenis-jenis makna dibagi menjadi makna leksikal, gramatikal, kontekstual, referensial dan non referensial, denotatif, konotatif, konseptual, asosiatif kata, istilah, idiom, serta makna peribahasa.

Makna idiomatik disebut juga dengan ungkapan, karena keduanya memiliki kandungan makna yang sama. Penggunaan bahasa idiomatik yang terdapat dalam berbagai karya dan artikel berupa sebuah istilah yang membutuhkan suatu penafsiran khusus. Untuk dapat memahami makna idiomatik, perlu diketahui dulu apa yang dimaksud dengan idiom. Chaer (1990: 74) menyatakan bahwa idiom adalah satuan-satuan bahasa (dapat berupa kata, frase, maupun kalimat) yang maknanya tidak dapat "diramalkan" dari makna leksikal maupun makna gramatikal. Idiom dibedakan menjadi dua macam, yaitu idiom penuh dan idiom sebagian.

Dalam bahasa Mandarin, idiom disebut juga dengan成语chéngyŭ. 成语chéngyŭ dibentuk dari berbagai unsur kelas kata, pada umumnya berkelas nomina dan verba. Kompenen makna paling dominan sebagai pembentuk成语chéngyŭ adalah nomina, baik yang menunjukkan benda konkret, maupun benda abstrak. Misalnya, berunsur hewan seperti kambing, kerbau, harimau, kelinci, naga, ular, bangau dan sebagainya; berunsur benda-benda alam seperti air, sawah, gunung, laut, langit, bumi, emas, api, salju, giok, musim semi, musim panas, musim gugur, musim dingin, dan sebagainya; berunsur tumbuh-tumbuhan seperti bunga, buah, rumput, pohon, kayu, dan sebagainya; berunsur anggota tubuh seperti mata, mulut, tangan, telinga, kepala dan sebagainnya; berunsur bilangan seperti satu, sepuluh, seratus, seribu dan lainnya (Chandra, 2019).

Artikel ini membahas makna idiomatik 成语chéngyǔ yang menggunakan unsur alam dalam buku 成语故事chéngyŭ gùshi. Pengertian chéngyǔ dalam 现代汉语 词典xiàndài hànyŭ cídiăn yang dikutip oleh Hasjem (2011:23), yaitu kelompok kata atau frase yang tetap, yang sudah digunakan dalam jangka panjang, bentuknya ringkas dan padat. 成语chéngyǔ biasanya terdiri dari empat karakter. Contoh: 
一诺千金 (Husen 2010:136)

yí nuò qiān jīn

Satu janji ribuan emas

Sebuah janji bagaikan ribuan emas (Makna Semantis)

'Janji yang paling berharga' (Makna Idiomatis)

成语chéngyǔ merupakan sari pati dari kebudayaan Cina yang telah berjalan lebih dari 5000 tahun, yang merupakan ungkapan dari cara berpikir, pandangan tentang idealisme, pandangan tentang etika, bahkan cara pemikiran taktik dan strategi militer dalam hubungan masyarakat (Husen 2010:1). Banyak orang yang mengalami kesulitan dalam mempelajari成语chéngyǔ karena kebanyakan成语 chéngyŭ yang terdiri dari empat kata akan sulit diuraikan artinya. Dalam menerjemahkannya tidak dapat diterjemahkan secara harfiah (literal) atau kata per kata.

成语Chéngyǔ memiliki makna idiomatik, yang dapat dibagi menjadi makna idiom penuh dan makna idiom sebagian. Berikut ini adalah beberapa contoh成语 Chéngyǔ yang mengandung makna idiom penuh dan idiom sebagian.

Contoh 成语chéngyǔ yang bermakna idiom penuh:

树大招风 (Huang Licheng, 2012:180)

shù dà zhāo fēng

Pohon besar mengundang angin

Pohon besar menjadi sasaran (Makna Semantis)

'Orang yang berkedudukan tinggi atau berpengaruh sering mendatangkan kerepotan atau kecelakaan bagi diri sendiri.' (Makna Idiomatis)

Contoh 成语chéngyǔ yang bermakna idiom sebagian:

调虎离山 (Huang Licheng, 2012:31)

diào hǔ lí shān

Memindahkan harimau meninggalkan gunung

Memancing harimau keluar gunung (Makna Semantis)

'Memancing musuh meninggalkan wilayahnya.' (Makna Idiomatis)

Penggunaan bahasa kiasan dalam 成语 chéngyŭ menimbulkan kesulitan bagi pelajar bahasa Mandarin dalam mengetahui dan memahami makna sebenarnya dari成语 chéngyǔ tersebut. Selain itu, penggunaan aksara dan bahasa kuno dalam 成语 chéngyǔ serta jumlah 成语 chéngyǔ yang banyak juga menjadi faktor lain dari minimnya pemahaman terhadap makna dari 成语 chéngyŭ. Mengingat jumlah 成语 chéngyǔ yang sangat banyak, 成语 chéngyǔ yang berunsur alam 
dipilih sebagai objek dalam penelitian ini karena 成语chéngyǔ berunsur alam banyak digunakan untuk mengambarkan perasaan, perbuatan, dan cara pandang manusia.

Tulisan ini memaparkan analisis 成语chéngyǔ yang menggunakan unsur alam sebagai salah satu unsur pembentuknya. Analisis mencakup makna idiomatik, yakni idiom penuh dan sebagian, fungsi sintaksis di dalam kalimat, serta fungsi dari penggunaan 成语chéngyǔ di dalam kehidupan sehari-hari. Tulisan ini diharapkan juga dapat membantu dalam memahami makna 成语chéngyǔ khususnya yang menggunakan unsur alam sebagai pembentuknya.

\section{METODOLOGI PENELITIAN}

Metode yang digunakan adalah metode kualitatif yang bersifat deskripstif. Metode deskriptif kualitatif merupakan metode yang bermaksud membuat deskripsi atau gambaran untuk memahami fenomena tentang apa yang dialami oleh subjek penelitian misalnya perilaku, persepsi, motivasi, tindakan, dan lainlain (Moleong, 2005: 6). Dalam penulisan ini, data penelitian dideskripsikan untuk melihat kenyataan sesungguhnya yang berupa tulisan, lalu dianalisis dan ditafsirkan dengan objektif untuk kemudian dideskripsikan dalam bentuk katakata.

Sumber data dalam penelitian ini adalah buku成语故事chéngyŭ gùshi karya Zhang Xingdong, diterbikan oleh 内蒙古人民出版社nèiměnggǔ rénmín chūbănshè pada bulan Januari tahun 2009. Korpus datanya adalah 成语chéngyǔ yang menggunakan unsur alam dalam成语故事chéngyǔ gùshi. Pengumpulan data dilakukan dengan menggunakan kartu data sehingga mempermudah pengidentifikasian data.

Teknik analisis data menggunakan teknik pilah unsur penentu (PUP). Teknik pilah unsur penentu merupakan teknik pilah, yakni alat yang digunakan adalah daya pilah yang bersifat mental yang dimiliki oleh peneliti sendiri (Sudaryanto, 1993: 21). Dalam penulisan ini teknik pilah unsur penentunya, yaitu referen dengan unsur alam sebagai alat penentu.

\section{PEMBAHASAN 成语 CHÉNGYǓ YANG BERUNSUR ALAM}

Unsur alam yang digunakan dalam 成语 chéngyŭ yang terdapat dalam buku成语 故事chéngyǔ gùshi adalah 秋qiū (musim gugur), 水shuǐ (air), 山shān (gunung), 海hăi (laut), 田tián (sawah), 风fēng (angin), 浪làng (ombak), 雪xuě (salju), 雨yŭ (hujan), 河hé (sungai), 地dì (tanah), 天tiān (langit), dan 天tiān (langit). Dari unsur alam di atas, yang paling banyak dipakai dalam 成语 chéngyŭ pada buku 成语故 事 chéngyǔ gùshi adalah水shuǐ (air). Masing-masing unsur alam yang digunakan mempunyai makna yang berbeda. 
Berdasarkan hasil analisis, makna yang lebih dominan dari 成语 chéngyŭ yang berunsur alam dalam buku 成语故事 chéngyŭ gùshi adalah makna idiom penuh. Berdasarkan makna dan fungsinya, dapat dikelompokan sebagai berikut:

A. Terdapat 12 成语 chéngyǔ memiliki makna idiom penuh yang berfungsi sebagai nasihat, yaitu杯水车薪bēi shuǐ chē xīn, 逼上梁山bī shàng liáng shān, 沧海桑田cāng hăi sang tián, 乘风破浪chéng fēng pò làng, 程门立雪 chéng mén lì xuě, 风吹草动fēng chuī căo dòng, 风雨同舟fēng yǔ tóng zhōu, 甘拜下风gān bài xià fēng, 脚踏实地jiǎo tà shí dì, 杞人忧天qĭ rén yōu tiān, 水滴石穿shuǐ dī shí chuān, dan䁇公移山yú gong yí shān.

B. Terdapat satu 成语 chéngyǔ memiliki makna idiom sebagian yang berfungsi sebagai nasihat, yaitu背水一战bèi shuĩ yí zhàn.

C. Terdapat lima 成语 chéngyǔ memiliki makna idiom penuh yang berfungsi sebagai sindiran, yaitu暗送秋波 àn sòng qiū bō, 覆水难收fù shuǐ nán shōu, 过河拆桥guò hé chāi qiáo, 近水楼台jìn shuǐ lóu tái, dan 名落孙山míng luò sūn shān.

D. Terdapat tiga 成语 chéngyǔ memiliki makna idiom penuh yang berfungsi sebagai pujian yaitu高山流水gāo shān liú shuĭ, 天衣无缝tiān yī wú fèng, dan雪中送炭xuě zhōng song tàn.

Dengan demikian, dalam buku 成语故事chéngyŭ gùshi terdapat 21 成语 chéngyŭ yang menggunakan unsur alam. Berikut 21 成语 chéngyǔ tersebut yang disajikan dalam tabel 1:

Tabel 1. chéngyǔ yang menggunakan unsur alam

\begin{tabular}{|c|c|c|c|c|}
\hline No & 成语Chéngyǔ & Makna Semantis & Makna Idiomatis & Fungsi \\
\hline 1. & $\begin{array}{c}\text { 暗送秋波 } \\
\text { àn sòng qiū bo }\end{array}$ & $\begin{array}{l}\text { Diam-diam } \\
\text { mengirimkan ombak } \\
\text { musim gugur }\end{array}$ & $\begin{array}{l}\text { Mengerling dengan } \\
\text { maksud menggoda }\end{array}$ & sindirian \\
\hline 2. & $\begin{array}{c}\text { 杯水车薪 } \\
\text { bēi shuĭ chē xīn }\end{array}$ & $\begin{array}{l}\text { Memadamkan api } \\
\text { segerobak kayu yang } \\
\text { terbakar dengan } \\
\text { secangkir air. }\end{array}$ & $\begin{array}{l}\text { Suatu usaha yang } \\
\text { sia-sia saja }\end{array}$ & nasihat \\
\hline 3. & $\begin{array}{c}\text { 背水一战 } \\
\text { bèi shulı yízhàn }\end{array}$ & $\underset{\text { air }}{\text { Bertarung melawan }}$ & $\begin{array}{l}\text { Bertarung hidup } \\
\text { atau mati }\end{array}$ & nasihat \\
\hline 4. & $\begin{array}{c}\text { 逼上梁山 } \\
\text { bi shàng liáng } \\
\text { shānn }\end{array}$ & $\begin{array}{l}\text { Terpaksa mendaki } \\
\text { gunung Liang }\end{array}$ & $\begin{array}{l}\text { Menghalalkan } \\
\text { segala cara untuk } \\
\text { mencapai tujuan }\end{array}$ & nasihat \\
\hline 5. & $\begin{array}{c}\text { 沧海桑田 } \\
\text { cāng hăi sang } \\
\text { tián }\end{array}$ & $\begin{array}{l}\text { Samudra berubah } \\
\text { menjadi sawah }\end{array}$ & $\begin{array}{l}\text { Dunia mengalami } \\
\text { perubahan besar, }\end{array}$ & nasihat \\
\hline
\end{tabular}


kehidupan yang tidak kekal

\section{乘风破浪}

6. chéng fēng pò làng

7. 程门立雪 chéng mén lì xuě

$$
\text { 风吹草动 }
$$

8. fêng chuī căo dòng

\section{风雨同舟}

9. fêng yǔ tóng zhōu

10. 覆水难收 fù shuǐ nán shōu

甘拜下风
11.
àn bài xià fēng 高山流水

12. gāo shān liú shuǐ

$$
\text { 高山流水 }
$$

13. gāo shān liú shui

14. 脚踏实地 jiăo tà shí di

15. 近水楼台 jìn shuľ lóu tái

名落孙山

16. míng luò sūn shān

17.

$$
\text { 杞人忧天 }
$$
qǔ rén yōu tiān

\section{水滴石穿}

18. shuǐ dī shí chuān

19. 天衣无缝 tiān ȳi wú fèng

雪中送炭

20. xuě zhōng song tàn

21. 愚公移山 yú gong yí shān
Menaiki angin memecahkan ombak

Salju bertumpuk didepan rumah Cheng

Tiupan angin menggerakgan rumput

Menghadapi badai dalam perahu yang sama

Air yang tumpah sulit dikumpulkan

Memberi hormat melawan angin

Gunung tinggi air mengalir

Membongkar jembatan setelah menyeberangi sungai Kaki menginjak tanah sebenarnya

Menara dekat sungai

Namanya berada di bawah Sun Shan

Orang dari Negara Qi mencemaskan alam

Air menetes menembus batu

Baju kayangan tanpa jahitan

Mengantar arang di tengah salju

Kakek Yu memindahkan gunung
Sangat berambisi; maju tak gentar

nasihat

Penghormatan kepada guru

nasihat

Rumor

nasihat

Tetap bersatu

dalam masa-masa sulit

Nasi sudah menjadi bubur,

menyesalpun tidak

sindiran ada gunanya

Mengakui

kekalahan

nasihat

Musik atau suara yang indah

pujian

Habis manis sepah dibuang

sindiran

Bersungguhsungguh

nasihat

Memanfaatkan

kedudukan seseorang

sindiran

Gagal dalam ujian sindiran

Ketakutan atau kegelisahan yang sindiran tidak semestinya Usaha yang terusmenerus akan mendatangkan nasihat keberhasilan

Tidak ada cacat celanya

pujian Memberikan bantuan tepat pada pujian waktunya

Di mana ada kemauan di situ ada jalan

nasihat The Idiomatic Meaning | 6 


\section{暗送秋波 ÀN SÒNG QIŪ BŌ}

Gelap kirim musim gugur ombak

Makna semantis: Diam-diam mengirimkan ombak musim gugur.

Makna idiomatis: Mengerling dengan maksud menggoda

成语Chéngyǔ 暗送秋波 àn sòng qiū bō mempunyai makna idiom penuh karena makna idiomatik sangat berbeda dengan makna harfiahnya. Dalam成语 chéngyǔ ini terdapat unsur alam 秋 qiū yang artinya 'musim gugur'. Berdasarkan lata belakang ceritanya, dijelaskan bahwa untuk menyusun strategi agar董卓Dǒng Zhuó dan吕布Lü Bù menjadi musuh, 王允Wáng Yǔn mengirimkan wanita tercantik, yaitu貂蝉Diāo Chán untuk mengoda kedua orang itu. 暗送àn song maksudnya melihat diam-diam dengan tatapan menggoda. 秋波qiū bō maksudnya menggambarkan mata seorang wanita cantik bagaikan ombak di musim gugur yang jernih dan bercahaya. Wanita tersebut mengerling genit melalui mata indah itu. 成语 Chéngyǔ ini berfungsi sebagai sindiran yang digunakan untuk menyindir seseorang yang mengerling genit kepada lawan jenis. Dalam penggunaan kalimat, 成语chéngyǔ ini juga berfungsi sebagai predikat (谓语wèiyǔ).

Contoh penggunaan 成语 chéngyǔ 暗送秋波àn sòng qiū bō dalam kalimat :

tā xiàng nà wèi shuàigē ànsòngqiūbō.

她向那位帅哥暗送秋波。

Dia hadap itu lelaki tampan gelap kirim musim gugur ombak

'la mengerling genit kepada lelaki tampan itu.

\section{杯水车薪 BËI SHUǏ CHË XĪN}

Gelas air gerobak kayu bakar

Makna Semantis: Memadamkan api segerobak kayu yang terbakar dengan secangkir air.

Makna Idiomatis: Suatu usaha yang sia-sia saja.

成语Chéngyǔ 杯水车薪bēi shuǐ chē xīn mempunyai makna idiom penuh karena makna idiomatiknya sangat berbeda dengan makna harfiahnya. Dalam 成语 chéngyǔ ini terdapat unsur alam 水shuǐ yang artinya 'air'. Latar belakang cerita di atas menggambarkan bahwa 赵大Zhào Dà telah melakukan hal yang sia-sia. Dari cerita tersebut juga dapat menjelaskan bahwa dengan kekuatan atau kemampuan yang kecil, untuk dapat mencapai tujuan yang besar, akan sangat sulit. Oleh karena itu, kita harus meningkatkan kekuatan atau kemampuan kita. 成语 Chéngyǔ ini dalam kalimat berfungsi sebagai predikat (谓语 wèiyǔ) dan 
objek (宾语bīnyŭ), serta sebagai nasihat yang digunakan untuk menasihati orang agar tidak melakukan hal yang sia-sia.

Contoh penggunaan 成语 chéngyǔ 杯水车薪bēi shuǐ chē xīn dalam kalimat (Huang Licheng 2012:4):

nà zuò fángwū zháohuǒle, xiāofáng yuán hái méiyǒu lái, jūmín yòng yī tǒng yī tǒng de

那座房屋着火了，消防员还没有来，居民用一桶一桶的

shuǐ jiùhuǒ, zhè shì bēishuǐchēxīn, wújìyúshì.

水救火, 这是杯水车薪, 无济于事。

Itu rumah terbakar, pemadan kebakaran petugas belum datang, sekitar orangorang menggunakan satu ember satu ember air menyelamatkan api, ini adalah gelas air gerobak kayu bakar tidak melewati di masalah.

'Rumah itu terbakar, petugas pemadam kebakaran belum datang, orang-orang di sekitar berusaha memadamkan api dengan air satu ember demi satu ember, ini hanya akan sia-sia saja.'

\section{背水一战 BĖI SHUǏ Yí ZHÀN}

Punggung air satu perang

Makna Semantis: Bertarung melawan air.

Makna Idiomatis: Bertarung hidup atau mati.

成语Chéngyǔ 背水一战bèi shuǐ yí zhàn mempunyai makna sebagian karena makna idiomatiknya masih dapat diartikan dari salah satu unsur pembentuknya, yaitu makna kata bertarung (战zhàn). Dalam 成语chéngyǔ ini terdapat unsur alam 水shuǐ yang artinya 'air'. Berdasarkan latar belakang ceritanya, dipaparkan bahwa韩信Hán Xìn menggunakan strategi ini untuk memaksa prajuritnya mengeluarkan semua kekuatan mereka, jika tidak mereka akan kehilangan nyawa. Setelah 韩信Hán Xìn menggunakan strategi tersebut, banyak jenderal yang menggunakan strategi perang ini. 成语Chéngyǔ ini dalam kalimat berfungsi sebagai predikat (谓语 wèiyǔ) dan atributif (定语dingyǔ) dan juga bersifat sebagai nasihat yang digunakan untuk menasihati agar pantang menyerah, 成语 chéngyŭ ini juga merupakan siasat atau kecerdikan dalam berperang.

Contoh penggunaan 成语 chéngyŭ 背水一战bèi shuǐ yí zhàn dalam kalimat:

wèile chénggōng, nǐ bìxū yǒu gè bèishuǐyīzhàn de tàidù.

为了成功, 你必须有个背水一战的态度。

Demi kesuksesan, kamu harus ada punggung air satu perang sikap.

'Demi keberhasilan, kamu harus bertarung hidup atau mati.' 


\section{逼上梁山 BĪ SHÀNG LIÁNG SHĀN}

Dipaksa naik gunung Liang

Makna Semantis: Terpaksa mendaki gunung Liang.

Makna Idiomatis: Menghalalkan segala cara untuk mencapai tujuan.

成语 Chéngyǔ逼上梁山bī shàng liáng shān mempunyai makna idiom penuh karena makna idiomatik seluruhnya berbeda dengan makna harfiahnya. Dalam 成语 chéngyǔ ini terdapat unsur alam 山shān yang artinya 'gunung'. Berdasarkan latar belakang ceritanya, dapat dilihat bahwa林冲Lín Chōng yang sebenarnya merupakan orang yang baik dan jujur, tetapi karena perbuatan dari 高俅Gāo Qiú dan anak angkatnya高衙内Gāo Yánèi, mengakibatkan 林冲Lín Chōng marah dan dendam kepada mereka. Terakhir 林冲Lín Chōng bergabung dengan rakyat yang berencana untuk melakukan pemberontakan, sehingga menjatuhkan Dinasti Song. Andaikan 高俅Gāo Qiú dan 高衙内Gāo Yánèi tidak melakukan perbuatan yang memaksa林冲Lín Chōng harus pergi ke Gunung Liang dan bertemu para pemberontak, maka Dinasti Song tidak akan hancur. 成语 Chéngyŭ ini dalam kalimat berfungsi sebagai predikat (谓语 wèiyŭ) dan atributif (定语 dingyŭ) dan juga sebagai nasihat yang digunakan untuk menasihati orang agar tidak bertindak berlebihan ataupun kejam sehingga memaksa orang lain untuk melakukan hal yang tidak baik atau melanggar hukum.

Contoh penggunaan 成语 chéngyǔ逼上梁山bī shàng liáng shān dalam kalimat: bié yǐwéi wǒ yuànyì zhème zuò, wǒ yěshì bèi bīshàngliángshān, shízài bùdéyǐ.

别以为我愿意这么做, 我也是被逼上梁山, 实在不得已。

Jangan anggap saya ingin ini melakukan, saya juga adalah terpaksa naik Gunung Liang, benar-benar tidak dapat dihentikan.

'Jangan berpikir saya ingin melakukan hal ini, saya juga terpaksa menghalalkan segala cara untuk mencapai tujuan, sudah tidak tahu harus bagaimana lagi.'

\section{沧海桑田 CĀNG HǍI SANG TIÁN}

Samudra murbei sawah

Makna Semantis: Samudra berubah menjadi sawah.

Makna Idiomatis: Dunia mengalami perubahan besar, kehidupan yang tidak kekal.

成语 Chéngyǔ 沧海桑田cāng hăi sang tián diucapkan oleh麻姑Má Gū ketika 王 芳平Wáng Fāngpíng menanyakan usianya. 成语 Chéngyǔ 沧海桑田cāng hăi sang tián mempunyai makna idiom penuh karena makna idiomatik sangat berbeda dengan makna harfiahnya. Dalam 成语 chéngyŭ ini terdapat unsur alam 海 hăi dan 田tián yang artinya 'laut' dan 'sawah'. Berdasarkan latar belakang ceritanya, dapat diketahui bahwa dari dahulu sampai saat ini, dunia ini

9 | Bambuti | Vol X | No. X | 2020 
mengalami banyak perubahan, contohnya cuaca; ada juga yang semula merupakan daratan, sekarang menjadi lautan atau-sebaliknya. 成语 Chéngyǔ ini dalam kalimat berfungsi sebagai predikat (谓语 wèiyǔ) dan objek (宾语bīnyŭ) dan juga berfungsi sebagai nasihat yang digunakan untuk menasihati orang-orang untuk mengerti bahwa dunia ini akan terus berubah dan kehidupan manusia tidak kekal.

Contoh penggunaan成语 chéngyǔ 沧海桑田cāng hăi sang tián dalam kalimat: zhè zuò xiăochéng shi ǰ̃ niánlái, cānghăisāngtián, biànhuà shizài tài dàle.

这座小城十几年来, 沧海桑田, 变化实在太大了。

Ini kecil kota belasan tahun datang, samudra murbei sawah, perubahan benar sangat banyak.

'Kota kecil ini dalam belasan tahun, mengalami perubahan besar dan luar biasa.'

\section{乘风破浪 CHÉNG FËNG PÒ LÀNG}

Naik angin pecah ombak

Makna Semantis: Menaiki angin memecahkan ombak.

Makna Idiomatis: Sangat berambisi; maju tak gentar.

成语 Chéngyǔ乘风破浪chéng fēng pò làng mempunyai makna idiom penuh karena makna idiomatik sangat berbeda dengan makna harfiahnya. Ketika kita sedang menghadapi masalah atau ujian apa pun, harus mempunyai keberanian untuk menghadapi dan melewatinya. Dalam 成语 chéngyǔ ini terdapat unsur alam 风fēng dan 浪làng yang artinya 'angin' dan 'ombak'. 成语 Chéngyǔ ini dalam kalimat berfungsi sebagai predikat (谓语 wèiyŭ) dan juga berfungsi sebagai nasihat yang digunakan untuk menasihati agar kita dapat menghadapi setiap ujian dan rintangan dengan berani dan dapat mencapai cita-cita yang diinginkan.

Contoh penggunaan 成语 chéngyǔ乘风破浪chéng fēng pò làng dalam kalimat: zài gōngzuò shàng, wǒmen yào gănyú chéngfēngpòlàng.

在工作上，我们要敢于乘风破浪。

'Dalam pekerjaan, kita harus maju tak gentar.'

\section{程门立雪 CHÉNG MÉN Lì XUĚ}

Pintu Cheng tumpuk salju

Makna Semantis: Salju bertumpuk didepan rumah Cheng.

Makna Idiomatis: Penghormatan kepada guru. 
成语 Chéngyǔ程门立雪chéng mén lì xuě mempunyai makna idiom penuh karena makna idiomatiknya sama sekali berbeda dengan makna harfiahnya. Berdasarkan latar belakang ceritanya, sebagai seorang murid tentunya harus menghormati gurunya. Seperti杨时 Yáng Shí dan 游䣷Yóu Cù, karena tidak ingin mengganggu gurunya tidur, maka mereka berdiri di depan pintu dalam keadaan sedang turun salju. Mereka lebih memilih kedinginan daripada mengganggu gurunya yang sedang tidur. Dalam 成语 chéngyǔ ini terdapat unsur alam 雪xuě yang artinya 'salju'. 成语 Chéngyǔ ini dalam kalimat berfungsi sebagai objek (宾 语bīnyŭ) dan atributif (定语dingyǔ) dan juga berfungsi sebagai nasihat yang digunakan untuk menasihati kita agar dapat menghormati guru yang telah mengajari kita.

Contoh penggunaan 成语 chéngyǔ程门立雪chéng mén lì xuě dalam kalimat:

xiànzài de niánqīng rén yǒu chéng mén lì xuě de jīngshén de yĭjīng bù duōle.

现在的年轻人有程门立雪的精神已经不多了。

Sekarang anak muda ada pintu Cheng tumpuk salju semangat sudah tidak banyak lagi.

'Anak muda sekarang, yang memiliki semangat menghormati guru dan pengetahuan sudah tidak banyak.'

\section{风吹草动 FEENG CHUİ CǍO DÒNG}

Tiupan angin menggerakan rumput

Makna Semantis: Tiupan angin menggerakgan rumput.

Makna Idiomatis: Rumor

Latar belakang 成语 chéngyǔ ini bercerita tentang kekhawatiran dan ketakutan yang dialami oleh 伍子胥Wǔ Zìxū sehingga dia tidak percaya kepada siapapun, termasuk orang yang dengan tulus ingin menolongnya. 成语 Chéngyǔ 风吹草动 fēng chuī căo dòng mempunyai makna idiom penuh karena makna idiomatik sangat berbeda dengan makna harfiahnya. Dalam 成语 chéngyǔ ini terdapat unsur alam 风fēng yang artinya 'angin'. 成语 Chéngyǔ ini dalam kalimat berfungsi sebagai objek (宾语bīnyŭ) dan atributif (定语dingyŭ), serta berfungsi sebagai nasihat yang digunakan untuk menasihati orang agar berhati-hati dengan kabarkabar yang tidak jelas, dapat tetap tenang dengan perubahan atau gerakan apapun.

Contoh penggunaan 成语 chéngyǔ 风吹草动fēng chuī căo dòng dalam kalimat (Huang Licheng 2012:40):

nà shí liánnián zhànluàn, ȳ̄ yǒu fēngchuīcăodòng, lăobăixìng nánmiăn jīnghuāng shīcuò.

那时连年战乱，一有风吹草动，老百姓难免惊愊失措。

11 | Bambuti | Vol X | No. X | 2020 
Itu waktu bertahun-tahun perang kacau, satu ada tiupan angin menggerakan rumput, rakyat sulit tidak panik takut.

'Pada waktu itu, bertahun-tahun dilanda kekacauan akibat perang, sehingga jika ada rumor, rakyat akan panik dan ketakutan.'

\section{风雨同舟 FËNG YǓ TÓNG ZHŌU}

Angin hujan sama perahu

Makna Semantis: Menghadapi badai dalam perahu yang sama.

Makna Idiomatis: Tetap bersatu dalam masa-masa sulit.

成语Chéngyŭ风雨同舟fēng yǔ tóng zhōu mempunyai makna idiom penuh karena makna idiomatik sangat berbeda dengan makna harfiahnya. 成语 Chéngyǔ ini mengambarkan orang yang melalui segala ujian dan rintangan bersama-sama baik suka maupun duka. Dalam 成语 chéngyŭ ini terdapat unsur alam 风fēng dan 雨yǔ yang artinya 'angin' dan 'hujan'. 成语 Chéngyǔ ini dalam kalimat berfungsi sebagai predikat (谓语 wèiyŭ) dan atributif (定语dingyǔ) dan juga berfungsi sebagai nasihat yang digunakan untuk menasihati orang agar menghargai orang yang memiliki jodoh dengan kita, apalagi orang itu adalah yang menemani kita dalam suka dan duka.

Contoh penggunaan 成语 chéngyŭ风吹草动fēng chuī căo dòng dalam kalimat (Huang Licheng 2012:41):

wǒmen fāshì yǔ zāimín fēngyǔtóngzhōu.

我们发誓与灾民风雨同舟。

Kami janji dengan korban bencana angin hujan sama perahu.

'Kami berjanji akan tetap bersatu dalam masa-masa sulit dengan para korban bencana.'

\section{覆水难收 FÙ SHUǏ NÁN SHŌU}

Tumpah air sulit dikumpulkan

Makna Semantis: Air yang tumpah sulit dikumpulkan.

Makna Idiomatis: Nasi sudah menjadi bubur, menyesalpun tidak ada gunanya.

Berdasarkan latar belakang cerita 成语 Chéngyǔ ini, digambarkan bahwa sebelumnya 朱买臣zhū Măichén diremehkan dan direndahkan oleh istrinya, tetapi setelah melihat 朱买臣zhū Mǎichén benar-benar menjadi pejabat dan hidup makmur, istrinya malu dan menyesal atas perbuatannya. 成语 Chéngyŭ覆 
水难收fù shuĩ nán shōu mempunyai makna idiom penuh karena makna idiomatik sangat berbeda dengan makna harfiahnya. 成语 Chéngyǔ ini mengambarkan bahwa penyesalan selalu datang di akhir, dan tidak dapat diperbaiki lagi. Dalam 成语 chéngyǔ ini terdapat unsur alam 水shuř yang artinya 'air'. 成语 Chéngyǔ ini dalam kalimat berfungsi sebagai predikat (谓语 wèiyŭ) dan objek (宾语bīnyŭ), serta berfungsi sebagai sindiran untuk menyindir perbuatan orang yang sudah terlanjur dilakukan dan tidak dapat diperbaiki lagi, yang ada hanyalah penyesalan.

Contoh penggunaan 成语 chéngyŭ覆水难收fù shuǐ nán shōu dalam kalimat:

shi yĭ rúcĭ, fùshuinánshōu, nǐ yě bùbì guòfèn bēishāng.

事已如此，覆水难收，你也不必过分悲伤。

Masalah sudah seperti ini, tumpah air sulit dikumpulkan, kamu juga tidak harus terlalu sedih.

'Masalahnya sudah seperti ini, nasi sudah menjadi bubur, menyesalpun tidak ada gunanya, kamu jangan terlalu bersedih lagi.'

\section{甘拜下风GĀN BÀI XIÀ FËNG}

Manis hormat bawah angin

Makna Semantis: Memberi hormat melawan angin.

Makna Idiomatis: Mengakui kekalahan.

Berdasarkan latar belakang ceritanya, digambarkan bahwa Raja Jin melupakan budi dari Raja Qin. Karena itu, Raja Qin memutuskan untuk menyerang kerajaan Jin. Akhirnya, Raja Jin dijadikan budak oleh Raja Qin, tetapi tidak kepada rakyat dan pejabat-pejabatnya, sehingga membuat mereka mengagumi keputusan Raja Qin dan benar-benar mengaku kalah. 成语 Chéngyǔ 甘拜下风 gān bài xià fēng mempunyai makna idiom penuh karena makna idiomatik sama sekali berbeda dengan makna harfiahnya. 成语 Chéngyǔ ini dalam kalimat berfungsi predikat ( 谓语 wèiyŭ) dan objek (宾语bīnyŭ) dan juga berfungi sebagai nasihat yang digunakan untuk menasihati orang yang berani untuk mengaku kekalahan. Dalam 成语 chéngyǔ ini terdapat unsur alam 风fēng yang artinya 'angin.'

Contoh penggunaan 成语 chéngyǔ甘拜下风 gān bài xià fēng dalam kalimat (Huang Licheng 2012:44):

tā páshān de běnlǐng, shéi yě bǐ bù shàng, wǒ gānbàixiàfēng.

他爬山的本领, 谁也比不上, 我甘拜下风。

Dia mendaki gunung kemampuan, siapa juga banding tidak naik, saya manis hormat bawah angin.

'Kemahirannya dalam mendaki gunung tidak ada yang bisa melawannya, terus terang saya mengaku kalah.'

13 | Bambuti | Vol X | No. X | 2020 


\section{高山流水 GĀO SHĀN LIÚ SHUǏ}

Tinggi gunung mengalir air

Makna Semantis: Gunung tinggi air mengalir.

Makna Idiomatis: Musik atau suara yang indah.

成语 Chéngyǔ 高山流水gāo shān liú shuǐ mempunyai makna idiom penuh karena makna idiomatiknya sangat berbeda dengan makna harfiahnya. Berdasarkan latar belakang ceritanya, dapat terlihat keindahan musik bagaikan bersatu dengan alam. Musik yang indah itu hanya dapat dimainkan oleh伯牙Bóyá, dan yang dapat memahami musik yang dimainkan oleh 伯牙Bóyá hanya 子期 Zĩqĩ. Setelah 子期 Zìqī meninggal, 伯牙Bóyá bagaikan kehilangan jiwanya. Oleh karena itu, ia memutuskan untuk tidak bermain musik lagi karena kesedihan yang dialaminya. Dalam 成语 chéngyǔ ini terdapat unsur alam 山shān dan 水shuǐ yang artinya 'gunung' dan 'air'. 成语 Chéngyǔ ini dalam kalimat berfungsi objek (宾语 bīnyǔ), serta berfungsi sebagai pujian yang digunakan untuk memuji indahnya melodi atau irama musik yang indah seperti alam ini.

Contoh penggunaan 成语 chéngyǔ高山流水gāo shān liú shuǐ dalam kalimat (Huang Licheng 2012:45):

tā gāngcái dànle zhège qǔzi, zhēnrú gāoshānliúshuĭ, měimiào jíle.

他刚才弹了这个曲子，真如高山流水，美妙极了。

Dia tadi memainkan ini lagu, benar seperti tinggi gunung mengalir air, indah ajaib sekali.

'Lagu yang dimainkannya tadi, bagaikan musik yang menyatu dengan alam, indah sekali.'

\section{高山流水 GĀO SHĀN LIÚ SHUǏ}

Lewat sungai bongkar jembatan

Makna Semantis: Membongkar jembatan setelah menyeberangi sungai.

Makna Idiomatis: Habis manis sepah dibuang.

成语 Chéngyǔ过河拆桥guò hé chāi qiáo mempunyai makna idiom penuh karena makna idiomatiknya sama sekali berbeda dengan makna harfiahnya. Dalam 成 语 chéngyǔ ini terdapat unsur alam 河hé yang artinya 'sungai'. 成语 Chéngyǔ ini dalam kalimat berfungsi sebagai predikat (谓语 wèiyŭ) dan objek (宾语bīnyŭ) dan juga berfungsi sebagai sindiran yang digunakan untuk menyindir orang yang melupakan budi atau kebaikan orang lain, serta melakukan hal yang 
bertentangan kepada orang yang berbudi itu.

Contoh penggunaan 成语 chéngyǔ过河拆桥guò hé chāi qiáo dalam kalimat (Huang Licheng 2012:55):

shiqing yī bàn chéng, jiù guòhéchāiqiáo, zhè zhǒng wàng'ēnfùyì de rén, qiān wàn yào

事情一办成，就过河拆桥，这种忘恩负义的人，千万要

tífáng.

提防。

Masalah satu kerjakan selesai, langsung lewat sungai bongkar jembatan, ini lupa budi orang, ribu puluhan ribu harus hati-hati.

'Setelah urusannya selesai, langsung habis manis sepah dibuang, orang yang melupakan budi seperti ini, benar-benar harus berhati-hati.'

\section{脚踏实地 JIǍO TÀ SHÍ Dì}

Kaki injak nyata bumi

Makna Semantis: Kaki menginjak tanah sebenarnya.

Makna Idiomatis: Bersungguh-sungguh.

Latar belakang cerita dari 成语 Chéngyǔ ini adalah kisah mengenai司马光Sìmă Guāng kecil yang sangat terkenal, dan menjadi sebuah cerita yang sering diberikan kepada anak-anak sebagai motivasi agar dapat belajar dengan giat, sehingga memiliki masa depan yang cemerlang. Cerita dari司马光Sīmă Guāng ini juga bertujuan untuk membentuk karakter setiap orang agar menjadi lebih baik. 成语 Chéngyǔ脚踏实地jiǎo tà shí dì mempunyai makna idiom penuh. Dalam 成语 chéngyǔ ini terdapat unsur alam 地 dì yang artinya 'bumi' atau 'tanah'. 成语 Chéngyǔ ini dalam kalimat berfungsi predikat (谓语 wèiyǔ), objek (宾语bīnyǔ), atributif (定语dingyǔ) dan keterangan (状语zhuàngyǔ) dan juga berfungsi sebagai nasihat yang digunakan untuk menasihati agar orang-orang dapat sesuai dengan realita dan bersungguh-sungguh, tidak berpura-pura atau melakukan hal yang penuh kebohongan.

Contoh penggunaan 成语 chéngyǔ脚踏实地jiăo tà shí dì dalam kalimat (Huang Licheng 2012:78):

wǒmen jì yào yǒu yuăndà de líxiăng, yòu yào jiăotàshídì de gàn.

我们既要有远大的理想, 又要脚踏实地的干。

Kita harus ada jauh besar impian, juga harus kaki injak nyata bumi kerjakan.

'Kita harus bercita-cita luhur dan bekerja sungguh-sungguh dan sesuai realita.' 


\section{近水楼台 JìN SHUǏ LÓU TÁl}

Dekat air menara

Makna Semantis: Menara dekat sungai.

Makna Idiomatis: Memanfaatkan kedudukan seseorang.

成语 Chéngyǔ 近水楼台jìn shuǐ lóu tái mempunyai makna idiom penuh karena makna idiomatik sangat berbeda dengan makna harfiahnya. Berdasarkan latar belakang ceritanya, 近水楼台jìn shuǐ lóu tái adalah sebuah 成语 chéngyǔ yang terdapat dalam syair atau puisi yang ditulis oleh苏麟Sū Lín. la merasa dilupakan oleh范仲淹Fàn Zhòngyān. Dalam 成语 chéngyǔ ini terdapat unsur alam 水shuĭ yang artinya 'air'. 成语 Chéngyǔ ini dalam kalimat berfungsi sebagai subjek (主 语zhǔyǔ), objek (宾语bīnyǔ) dan atributif (定语dingyǔ), serta berfungsi sebagai sindiran yang digunakan untuk menyindir orang yang memanfaatkan kekuasaan atau wewenang agar dapat memenuhi keinginan pribadi.

Contoh penggunaan 成语 chéngyǔ近水楼台jìn shuǐ lóu tái dalam kalimat :

yīn wéi shì jìnshuǐlóutái, tā hěn kuài dì jiù qǐng lái zhù bàng bì de diànnăo jìshī lái bāng

因为是近水楼台，他很快地就请来住棒壁的电脑技师来帮

tā xiū diànnăo.

他修电脑。

Karena adalah dekat air menara, dia sangat cepat mengundang datang tinggal hebat dinding komputer teknis datang bantu dia perbaiki komputer.

'Karena memanfaatkan kedudukan seseorang, dia dengan cepat dapat mengundang seorang teknisi komputer untuk memperbaiki komputernya.'

\section{名落孙山 MÍNG LUÒ SŪN SHĀN}

Nama bawah Sun Shan

Makna Semantis: Namanya berada di bawah Sun Shan.

Makna Idiomatis: Gagal dalam ujian.

成语 Chéngyǔ名落孙山míng luò sūn shān mempunyai makna idiom penuh karena makna idiomatiknya sangat berbeda dengan makna harfiahnya. Berdasarkan latar belakang ceritanya, dikisahkan bahwa 孙山Sūn Shān mendapatkan peringkat terakhir dalam ujian negara tersebut, dan anak tetangganya mempunyai peringkat di bahwa孙山Sūn Shān yang artinya tidak lulus. Dalam 成语 chéngyǔ ini terdapat unsur alam山shān yang artinya 'gunung'. 成语 Chéngyǔ ini dalam kalimat berfungsi sebagai predikat (谓语 wèiyǔ), atributif 
(定语dingyŭ) dan keterangan (状语zhuàngyŭ), serta berfungsi sebagai sindirian yang digunakan untuk menyindir orang yang gagal lulus ujian.

Contoh penggunaan 成语 chéngyǔ名落孙山míng luò sūn shān dalam kalimat (Huang Licheng 2012:119):

tā zài rùxué kăoshì zhōng míngluòsūnshān.

他在入学考试中名落孙山。

Dia masuk sekolah ujian tengah nama bawah Sun Shan.

'Dia gagal dalam ujian masuk sekolah.'

\section{杞人忧天 QǏ RÉN YŌU TIĀN}

Negara Qi cemas langit

Makna Semantis: Orang dari Negara Qi mencemaskan alam.

Makna Idiomatis: Ketakutan atau kegelisahan yang tidak semestinya.

成语 Chéngyǔ杞人忧天qǔ rén yōu tiān mempunyai makna idiom penuh karena makna idiomatiknya berbeda dengan makna harfiahnya. Berdasarkan latar belakang ceritanya, ada orang yang khawatir langit akan runtuh, ini merupakan hal yang tidak perlu dikhawatirkan karena dari dulu sampai sekarang dan masa yang akan datang, langit tidak akan runtuh. Kegelisahan yang berlebihan itu membuat dia jatuh sakit dan meninggal karena hal yang tidak perlu dikhawatirkan. Dalam 成语 chéngyŭ ini terdapat unsur alam 天tiān yang artinya 'langit'. 成语 Chéngyǔ ini dalam kalimat berfungsi sebagai predikat (谓语 wèiyǔ) dan keterangan (状语zhuàngyǔ), serta berfungsi sebagai nasihat yang digunakan untuk menasihati orang agar tidak khawatir, gelisah atau takut terhadap hal yang tidak mungkin terjadi ataupun hal yang belum terjadi, jika hal yang dikhawatirkan terjadi juga harus dihadapi dengan berani.

Contoh penggunaan 成语 chéngyǔ杞人忧天qǔ rén yōu tiān dalam kalimat (Huang Licheng 2012:137):

tā dānxīn zhège dăo huì lùchén, zhǔnbèi líkāi zhèlĭ, zhēnshi qürényōutiān.

他担心这个岛会陆沉，准备离开这里，真是杞人忧天。

Dia khawatir ini pulau akan tenggelam, bersiap-siap meninggalkan ini tempat, benar-benar adalah Negara Qi cemas langit.

'Dia khawatir pulau ini akan tenggelam, lalu bersiap-siap meninggalkan pulau ini, ini benar-benar ketakutan yang tidak semestinya.' 


\section{水滴石穿 SHUǏ DĪ SHÍ CHUĀN}

Air tetes batu tembus

Makna Semantis: Air menetes menembus batu.

Makna Idiomatis: Usaha yang terus-menerus akan mendatangkan keberhasilan.

成语 Chéngyǔ水滴石穿 shuǐ dī shí chuān mempunyai makna idiom penuh karena makna idiomatiknya sangat berbeda dengan makna harfiahnya. Dalam 成语 chéngyǔ ini terdapat unsur alam 水shuř yang artinya 'air'. 成语 Chéngyǔ ini dalam kalimat berfungsi sebagai atributif (定语dingyǔ) dan juga berfungsi sebagai nasihat yang digunakan untuk menasihati orang-orang agar pantang menyerah dan terus berusaha.

Contoh penggunaan 成语 chéngyǔ水滴石穿shuǐ dī shí chuān dalam kalimat (Huang Licheng 2012:181):

zhǐyào jiānchí bùxiè, kèkŭ nǔli, zirán shuĭdīshíchuān.

只要坚持不懈, 刻苦努力, 自然水滴石穿。

Hanya harus tidak menyerah, keras berusaha, dengan sendirinya air tetes batu tembus.

'Asal mau bertahan untuk tidak menyerah, berusaha keras, maka usaha yang terus menerus dilakukan itu akan mendatangkan keberhasilan.'

\section{天衣无缝 TIĀN YĪ WÚ FÈNG}

Langit baju tidak jahit

Makna Semantis: Baju kayangan tanpa jahitan.

Makna Idiomatis: Tidak ada cacat celanya.

Berdasarkan lata belakang ceritanya, dipaparkan bahwa seorang dewi yang bernama织女Zhī Nǘ turun ke dunia dan bertemu dengan 郭翰Guō Hàn. Karena 郭翰Guō Hàn terlihat tidak percaya dan curiga kepadanya, maka 织女Zhī Nü meminta郭翰Guō Hàn untuk melihat bajunya, sehingga郭翰Guō Hàn menyadari bahwa baju yang dipakai oleh织女Zhī Nü tidak seperti pakaian manusia. 成语 Chéngyǔ天衣无缝tiān yī wú fèng mempunyai makna idiom penuh karena makna idiomatik berbeda dengan arti harfiahnya. Dalam 成语 chéngyǔ ini terdapat unsur alam 天tiān yang artinya 'langit'. 成语 Chéngyǔ ini dalam kalimat berfungsi sebagai predikat (谓语 wèiyǔ), atributif (定语dìngyǔ) dan keterangan (状语 zhuàngyǔ), serta berfungsi sebagai pujian yang digunakan untuk memuji sebuah benda, tindakan, hasil karya dan lainnya yang tidak ada cacat celanya, atau sempurna. 
Contoh penggunaan 成语 chéngyǔ天衣无缝tiān yī wú fèng dalam kalimat (Huang Licheng 2012:192):

zhè piān wénzhāng lùnzhèng yánmi, tiānyīwứèng.

这篇文章论证严密, 天衣无缝。

Ini karangan argumen ketat, langit baju tidak jahit.

'Karangan ini tidak ada cacat celanya, argumentasinya tepat dan padat.'

\section{雪中送炭XUĚ ZHŌNG SONG TÀN}

Salju tengah antar arang

Makna Semantis: Mengantar arang di tengah salju.

Makna Idiomatis: Memberikan bantuan tepat pada waktunya.

Latar belakang 成语 Chéngyŭ ini adalah berupa syair yang menceritakan sikap Kaisar太宗Tài Zōng, caranya memerintah pada zaman Dinasti Song yang patut untuk diteladani, serta karakternya yang sangat sederhana dalam kehidupan. Cerita ini merupakan salah satu cerita terkenal pada zaman Dinasti Song. 成语 Chéngyǔ 雪中送炭xuě zhōng song tàn mempunyai makna idiom penuh karena makna idiomatiknya sangat berbeda dengan makna harfiahnya. Dalam 成语 chéngyǔ ini terdapat unsur alam 雪 xuě yang artinya 'salju'. 成语 Chéngyǔ ini dalam kalimat berfungsi sebagai predikat (谓语 wèiyŭ), objek (宾语bīnyǔ), dan atributif (定语dingyǔ), serta berfungsi sebagai pujian yang digunakan untuk memuji tindakan seseorang yang memberikan bantuan tepat waktu. Sama seperti tindakan Kaisar 太宗Tài Zōng yang memberikan bantuan tepat pada waktunya, sehingga membuat rakyat terharu dan berterima kasih kepadanya.

Contoh penggunaan 成语 chéngyŭ雪中送炭xuě zhōng song tàn dalam kalimat : tā de jǔdòng hăobǐ xuězhōngsòngtàn, gěile wǒmen mòdà de bāngmáng.

她的举动好比雪中送炭, 给了我们莫大的帮忙。

Dia perbuatan baik banding salju tengah antar arang, membuat kita besar bantuan.

'Perbuatannya sama seperti memberikan bantuan tepat pada waktunya, memberikan kita bantuan yang sangat besar.'

\section{愚公移山 YÚ GONG Yí SHĀN}

Kakek Yu pindah gunung

Makna Semantis: Kakek Yu memindahkan gunung.

19 | Bambuti | Vol X | No. X | 2020 
Makna Idiomatis: Di mana ada kemauan di situ ada jalan.

成语 Chéngyǔ愚公移山yú gong yí shān mempunyai makna idiom penuh karena makna idiomatiknya sangat berbeda dengan makna harfiahnya. Tekad dan semangat Kakek Yu yang pantang menyerah menjadi semangat yang harus diteladani. Dalam 成语 chéngyǔ ini terdapat unsur alam 山shān yang artinya 'gunung'. 成语 Chéngyǔ ini dalam kalimat berfungsi sebagai subjek (主语zhǔyǔ), objek (宾语bīnyǔ) dan atributif (定语dingyǔ) dan juga berfungsi sebagai nasihat, digunakan untuk menasihati agar tidak cepat menyerah dan terus berjuang untuk mencapai impian.

Contoh penggunaan 成语 chéngyŭ愚公移山yú gong yí shān dalam kalimat:

fāyáng yúgōngyíshān de jīngshén, găizào jiāxiāng miànróng.

发扬愚公移山的精神, 改造家乡面容。

Kembangkan Kakek Yu pindah gunung semangat, mengubah kampung halaman tampilan.

'Mengembangkan semangat yang pantang menyerah dan tidak takut susah, mengubah tampilan kampung halaman.'

\section{SIMPULAN}

Pada umumnya 成语 Chéngyǔ memiliki makna idiom penuh. Semua unsur pembentuknya tidak mencerminkan makna idiomatiknya.

成语 Chéngyǔ dapat digunakan untuk menyampaikan nasihat, sindiran dan pujian yang tidak dapat disampaikan secara langsung, karena jika disampaikan secara langsung dapat menyinggung perasaan orang lain atau pun membuat orang lain menjadi iri karena dipuji secara langsung. Oleh karena itu, orang-orang Tionghoa zaman dahulu ingin menyampaikannya secara lebih halus dan menyederhanakannya menjadi empat karakter/huruf Han (汉字hànzı) saja, namun tidak mengurangi makna atau maksud yang ingin disampaikan.

成语 Chéngyǔ merupakan sebuah karya yang diberikan oleh orang-orang zaman dahulu untuk mengambarkan kondisi atau lingkungan pada zaman masingmasing 成语 chéngyǔ. Ada 成语 chéngyǔ yang mengambarkan kondisi politik, ada yang mengambarkan kondisi ekonomi, ada yang mengambarkan kondisi lingkungan dan masyarakat, ada yang mengambarkan kondisi pendidikan pada sebuah kerajaan atau negara. Ada yang mengambarkan kondisi alam dan cuaca, pemandangan pada sebuah tempat, ada yang mengambarkan penderitaan masyarakat akibat perang dan lainnya, ada juga yang mengambarkan perasaan seseorang seperti cinta, kecewa, kagum, marah, takut, sedih dan lain sebagainya. Selain itu, juga dapat digunakan sebagai taktik atau strategi perang, serta dapat digunakan untuk mengambarkan kejahatan pejabat atau pun musuh.

The Idiomatic Meaning | 20 


\section{DAFTAR PUSTAKA}

Chaer, Abdul. 1990. Pengantar Semantik Bahasa Indonesia. Jakarta: Rineka Cipta.

Cipta. 2013. Pengantar Semantik Bahasa Indonesia. Jakarta: Rineka 2014. Linguistik Umum Edisi Revisi. Jakarta: Rineka Cipta.

Chandra, Yulie Neila. 2019. Telaah Semantik Chengyu (成语) Dalam Buku “Pepatah Tionghoa Kebijaksanaan Chengyu” (Zhongguo Chengyu中国成语 ). Prosiding Seminar Hasil Penelitian 2018/2019. Universitas Darma Persada, Jakarta.

Departemen Pendidikan Nasional. 2007. Kamus Besar Bahasa Indonesa Edisi III. Jakarta: Balai Pustaka.

Djajasudarma, Fatimah. 2009. Makna Leksikal dan Makna Gramatikal. Bandung: Refika Aditama.

Hardiyanto. 2008. Leksikologi. Yogyakarta. Penerbit: Kanwa.

Hasjem, Anita. 2011. Analisis Gaya Bahasa Pada Idiom Bahasa Mandarin. Skripsi. Universitas Sumatra Utara, Medan.

Hu Mingyang. 2000. 语言学概论Yǔyánxué gàilùn. Beijing: 语文出版社Yǔwén chūbănshè.

Huang Borong. 1997. Xiàndài Hànyǔ 《现代汉语》Bahasa Mandarin Modern. Beijing: Higher Education Press.

Huang Borong dan Liao Xudong. 2007. 现代汉语-上册Xiàndài Hànyǔ- shàngcè. Beijing: 高等教育出版社Gāoděng jiàoyù chūbănshè.

Huang Lichen. 2012. Kamus Idiom Tionghoa Indonesia. Tangerang: Harapan Jaya.

Kridalaksana, Harimurti. 2008. Kamus Linguistik. Jakarta: Gramedia Pustaka Utama.

Leman. 2007. Memahami Adversity Quotient. Anima (Indonesian Psychological Journal).

Ling, Mei. 2014. Analisis Idiom Empat Aksara Bahasa Mandarin yang Menggunakan Numeralia Berdasarkan Makna Konotasi dan Fungsinya. Skripsi. Universitas Kristen Maranatha, Bandung.

Ma Guofan. 1983. 成语Chengyu. Mongolia: 内蒙古人民出版社Nèiménggǔ rénmín chūbănshè.

Martinet, Andre. 1987. Ilmu Bahasa. Yogyakarta: Kanisius.

Moleong, Lexy. 2005. Metodologi Penelitian Kualitatif. Bandung: PT. Remaja Rosdakarya.

Nurul Alfiyah, Widuri. 2017. Analisis Makna Chengyu yang Menggunakan Unsur Binatang Berdasarkan Konotasi dan Fungsinya. Skripsi. Universitas Negeri Semarang, Semarang.

Palmer, F. R. 1981. Semantics. Cambridge: Cambridge University Press.

Pateda, Mansoer. 2010. Semantik Leksikal. Jakarta: Rineka Cipta.

Peng, Tan Huay. 2015. Kisah dan Makna Idiom China. Jakarta: PT. Gramedia Pustaka Utama. 
Rosarina. 2008. Analisis Pemahaman Peribahasa China pada Mahasiswa Jurusan Sastra China Universitas Bina Nusantara. Skripsi Universitas Bina Nusantara, Jakarta.

Sudaryanto. 1993. Metode dan Aneka Teknik Analisis Bahasa. Yogyakarta: Duta Wacana University Press

Sugiyono. 2005. Memahami Penelitian Kualitatif. Bandung: CV. Alfabeta. 2017. Metode Penelitian Kuantitatif, kualitatif, dan R\&D. Bandung: CV. Alfabeta.

Tang, Jianxiong. 2007. 现代汉语 Xiàndài Hànyǔ. Hebei: 河北人民出版社 Hēběi Rénmín Chūbănshè.

TKS, Husen. 2010. Asal Cerita Peribahasa Tionghoa 1. Serang: Tekad Mandiri. 2015. Asal Cerita Peribahasa Tionghoa 2. Serang: Tekad Mandiri. Mandiri.

Zhang, Xingdong. 2008. 成语故事chéngyŭ gùshi. Mongolia: 内蒙古人民出版社 Nèiménggǔ rénmín chūbănshè.

Zhou, Jian dan Du, Xiaolu. 2006. 6. 绘图注音版成语三百则Huitú zhùyīn băn chéngyǔ sānbǎi zé. Guangdong: 暨南大学出版社Jìnán dàxué chūbănshè. 